\title{
Riobaldo rememorando para viver o que faltava
}

\section{Rosilene Silva da Costa*}

\begin{abstract}
Resumo: Este ensaio tem como objeto de estudo o romance Grande Sertão: Veredas, de Guimarães Rosa. Serão discutidos aspectos referentes ao processo de rememoração e autoconhecimento da personagem principal, Riobaldo. $\mathrm{O}$ ensaio será dividido em três partes, nas quais trabalharemos a constituição da identidade de Riobaldo, a sua velhice, e a narração de sua história.
\end{abstract}

Palavras-Chave: identidade; velhice; narração; autoconhecimento; rememoração.

\begin{abstract}
This essay has as its main aim of analysis the novel Grande Sertão:Veredas, by Guimarães Rosa. We will discuss some topics referring to the process of reminiscence and self-knowledge of the main character, Riobaldo. This essay is divided in three parts, in which we will work on the constitution of Riobaldo's identity, his old age, and the narration of his story.
\end{abstract}

Keywords: identity; old age; self-knowledge; reminiscences.

Os indivíduos realizam, a cada momento, reelaborações daquelas recordações que melhor lhes permitem estruturar o seu presente, desta forma o passado se refaz constantemente. Na memória estão guardadas as lembranças, nela estão salvos os arquivos do passado, que revisitados conduzem a escolhas e possibilidades de construção do futuro. Sob a perspectiva de visitar o passado para afirmar-se enquanto sujeito, portador de uma identidade e de uma história, analisaremos a personagem Riobaldo de Grande Sertão: Veredas, de Guimarães Rosa.

A narrativa de Grande sertão: Veredas constrói-se segundo o desejo do narrador de compreender-se e de compreender a vida. Riobaldo narra a fim de atingir o autoconhecimento e de desvelar o sentido que lhe é oculto do mundo.

Dividiremos este ensaio em três partes, que se embasarão nas falas da personagem sobre quem ele afirma ser, sobre a sua velhice, e sobre o que ele pensa do ato de contar a sua história.

\section{Riobaldo: produto do sertão}

\footnotetext{
* Graduada em Letras pela UFRGS e mestranda do PPG-LET UFRGS na área de Literatura Portuguesa e Literaturas Luso-africanas. E-mail: lenecostas@hotmail.com
} 
Pensar em identidade nos dias atuais é arriscar-se em uma estrada cheia de armadilhas, ou, em termos mais objetivos, em território de sentidos complexos, deslizantes e em constante transformação. Vivemos em um tempo onde muitas são as idéias a respeito de identidade, as quais estão vinculadas ao conceito de subjetividade. Estes conceitos e idéias perpassam diversas áreas do conhecimento: educação, economia, história, filosofia, psicologia, crítica literária, estudos culturais, etc. De forma geral, estes estudos acabam por se orientar, basicamente, por duas linhas teóricas de pensamento: linha hegeliana, que vê o sujeito em sua pluralidade, ou seja, a identidade é vista como forma de totalização ou completude do heterogêneo; e a linha pós-moderna, na qual o sujeito é visto em sua complexidade, logo a identidade está vinculada à instabilidade, descontinuidade, abertura e fragmentação (cf. HALL, 2006).

O senso comum considera a identidade de um sujeito a partir de alguns fatores que seriam de alguma forma preponderantes (não determinantes) de sua formação: espaço geográfico de origem, a língua materna, a comunidade (família, raça, profissão, classe social) e os costumes (estilo de vida, religião) herdados da tradição. A literatura tende a caracterizar os indivíduos desta forma, e, no caso brasileiro, desde os primeiros intentos literários, buscava-se a criação de personagens que representassem o Brasil; mais adiante buscou-se a representação de tipos regionais.

Neste sentido pensamos que Grande Sertão: Veredas insere-se no rol de obras que vêm contribuir para a formação destes grupos característicos brasileiros, embora não nos apresente uma personagem que seja um tipo social. Em Grande Sertão: Veredas, Guimarães Rosa utiliza procedimentos relativos à memória individual e à memória coletiva. Estes procedimentos são atuantes e complementares para a construção de uma 'possível' identidade sertaneja, isto é: de um lado, o escritor recorre a elementos da memória e da tradição na reconstituição de uma pretensa identidade individual; de outro, há uma contribuição, voluntária ou não, para construir ou reforçar a identidade coletiva do cangaceiro, que embora, legalmente, tenha deixado de existir, é uma identidade em constante mudança e recriação.

O sertanejo Riobaldo, narrador e personagem central da obra, não pode ser visto como o conselheiro proposto por Walter Benjamin (1985), mas ele inscreve-se no grupo de pessoas que têm alguma coisa a falar e que somente dizendo poderão agir no mundo a fim de transformá-lo e de se autotransformar.

Riobaldo define-se como um sertanejo autônomo, filho de pai ilegítimo como muitos sertanejos, que se inventou na arte de explorar idéias. Os sentimentos de Riobaldo são, na maior parte das vezes, nobres; conforme ele nos conta. Essa nobreza de sentimentos ele usa 
para justificar suas ações mais violentas e mesmo para exemplificar o porquê de algumas atitudes. Ele nega o fato de ter sido assassino, atribuindo esse predicativo às práticas de fofoca do povo da região: "Não sou assassino. Inventaram em mim aquele falso, o senhor sabe como é esse povo" (ROSA, 2001, p.177).

Mesmo sendo velho, Riobaldo ainda se recorda da morte da mãe, pois além de ser a morte de um ente muito querido, ela significou uma total mudança na vida do adolescente. Quando recorda a morte da mãe, a personagem relembra detalhes climáticos, que tanto servem para dar credibilidade ao que está contando, quanto são metáforas do sentimento experimentado naquele momento. A chuva metaforiza as lágrimas derramadas, a tristeza e a dor sentidas pelo falecimento da progenitora. Por outro lado, a chuva também vem prenunciar um novo tempo, uma nova temperatura na vida do adolescente Riobaldo.

O seguinte é simples. Minha mãe morreu - apenas a Bigrí, era como ela se chamava. Morreu, num dezembro chovedor, aí foi grande a minha tristeza. Mas uma tristeza que todos sabiam, uma tristeza do meu direito. De desde, até hoje em dia, a lembrança de minha mãe às vezes me exporta. Ela morreu, como a minha vida mudou para uma segunda parte. (ibidem, p.126-127)

Com a morte da mãe a vida do menino vira para a segunda parte: ele segue para morar com o padrinho, que descobre ser seu pai, é matriculado na escola e depois de algum aprendizado é entregue para ser professor de Zé Bebelo, daí advindo o seu contato com a jagunçagem. A sua vida de jagunço é levada sem ter medo, embora não se considere um homem de muitas coragens. O medo é um sentimento que perpassa as falas de Riobaldo enquanto narra sua história. Ele não tinha medo de morrer, de participar da vida perigosa dos jagunços. O medo era de errar, pois naquela situação qualquer passo em falso era suficiente para perder a vida ou tudo o que já havia sido conquistado:

Acho que eu não tinha conciso medo dos perigos: o que eu descosturava era medo de errar - de ir cair na boca dos perigos por minha culpa. Hoje, sei: medo meditado - foi isto. Medo de errar. Medo de errar é que é a minha paciência. Mal. O senhor fia? Pudesse tirar de si esse medo-de-errar, a gente estava salva. O senhor tece? Entenda meu figurado. Conforme lhe conto: será que eu mesmo já estava apegado de costume conjunto de ajagunçado? Será, sei. (ibidem, p.201)

O jagunço considera que sua vida foi levada desta maneira por ser essa sua sina, seu destino, e marca desta forma o status social, pois não tinha como ser de outro jeito vivendo naquele sertão. Com a afirmativa: "Mas levei minha sina. Mundo, o em que estava, não era para gente: era um espaço para os de meia-razão" (ibidem, p.330), Riobaldo denuncia a jagunçagem e a vida no sertão como uma coisa que não poderia ser vivida por pessoas em seu estado normal. Embora ele esteja marcando com a idéia de loucura, e em outras passagens 
com a história do pacto, podemos inferir que o que leva os homens a esta vida de violência é a condição social e a ambição.

O próprio Riobaldo não se sentia feliz com a sua condição de jagunço, pois, pelo que vemos, houve um investimento para que ele entrasse no mundo das letras, no sentido de ter estudado. O jagunço não estava satisfeito consigo próprio, chegando a revelar repulsa por si mesmo e desconfiança para com os outros: "De que é que adiantava, se não, estatuto de jagunço? Ah, era. Por isso eu tinha grande desprezo de mim, e tinha cisma de todo mundo. Apartado. De Zé Bebelo, mais do que de todos" (ibidem, p.420).

$\mathrm{O}$ sertanejo, mesmo quando transformado em jagunço, demonstra interesse pelos livros. Em uma fazenda que o bando invadiu ele é atraído por um livro, o qual pede emprestado ao dono, marcando em sua fala ao doutor, que o escuta, que o proprietário do livro era analfabeto. Riobaldo enfatiza ainda que este foi o primeiro romance lido por ele:

Mas o dono do sítio que não sabia ler nem escrever, assim mesmo possuía um livro, capeado em couro, que se chamava o "Senclér das ilhas", e que pedi para deletrar nos meus descansos. Foi o primeiro desses que encontrei, de romance, porque antes eu só tinha conhecido livro de estudo. Nele achei outras verdades, muito extraordinárias. (ibidem, p.396)

Riobaldo é um homem fechado, calado, e parece que sisudo. Deseja contar sua vida para alguém que vá ouvir sua história sem interferência, sem atribuir juízo de valor e que se contente em ouvir o que ele está contando. O seu hábito não é conversar com pessoas de fora, tanto é que pede para o seu ouvinte desculpar seu jeito de contar. Ele conta resumindo, trazendo os fatos que lhe interessam e que poderão servir para sua libertação. Tem um relacionamento com o compadre Quelemém, mas não gosta de como o companheiro de conversas quer saber das coisas.

Essas coisas todas se passaram tempos depois. Talhei de avanço, em minha história. O senhor tolere minhas más devassas no contar. É ignorância. Eu não converso com ninguém de fora, quase. Não sei contar direito. Aprendi um pouco foi com compadre meu Quelemém, mas ele quer saber tudo diverso: quer não é o caso inteirado em si, mas a sobre-coisa, a outra-coisa. Agora, neste dia nosso, com o senhor mesmo - me escutando com devoção assim - é que aos poucos vou indo aprendendo a contar corrigido. E para dito volto. Como eu estava, com o senhor no meio dos Hermógenes. (ibidem, p.212)

Riobaldo acredita que "confusa é a vida da gente" (ibidem, p.206). Ele se analisa e pede que o ouvinte o abone: "tolere e releve estas palavras minhas de fúria; mas, disto, sei, era assim que eu sentia, sofria. Eu era assim. Hoje em dia, nem sei se sou assim, mais" (ibidem, p.204). Riobaldo anseia um dia esquecer sua vida de jagunço, mas tem consciência de que precisa passar pela confissão para que ela seja apagada: "Algum dia depois de hoje, hei de esquecer aquilo" (ibidem, p. 408). 
O fazendeiro Riobaldo, ex-jagunço sabe que viver é perigoso e adverte o jovem doutor que viver é o ato de aprender-a-viver, e se resume como sendo um produto do sertão:

O senhor escute meu coração, pegue no meu pulso. O senhor avista meus cabelos brancos... Viver - não? - é muito perigoso. Porque ainda não sabe. Porque aprender-a-viver é que é o que viver, mesmo. O sertão me produziu, depois me enguliu, depois me cuspiu do quente da boca...

O senhor crê na minha narração? (ibidem, p.601)

\section{Velhice: tempo de balanço}

Ecléa Bosi citando Emile Durkheim diz que "o velho não se contenta, em geral, de aguardar passivamente que as lembranças o despertem, ele procura precisá-las, ele interroga outros velhos, compulsa seus velhos papéis, suas antigas cartas e, principalmente, conta aquilo de que se lembra quando não cuida de fixá-lo por escrito" (BOSI, 1996. p.23). A velhice é um momento de descanso e balanço. Na maior parte das sociedades, o velho é aquele que tem um conselho a dar, pois ele já vivenciou muitas coisas, adquiriu experiência e conhecimento a ponto de ser o mestre dos mais jovens. Aproximamos os velhos do narrador proposto por Walter Benjamim (1985).

Quando nos achegamos do fazendeiro Riobaldo, rico por herança, paternidade desconhecida, órfão de mãe (ainda menino), ex-jagunço, encontramos um velho que "carece de ter sua aragem de descanso" (ROSA, 2001, p.26). Riobaldo, porém, não é exatamente o velhinho conselheiro: ele conta sua vida fazendo um balanço para ele mesmo. Em alguns momentos ele até dá algumas dicas para o seu ouvinte, mas a sua preocupação não está centrada no outro, no que ele poderá fazer com sua história, o narrador está interessado em se libertar de um passado que o acusa. O velho Riobaldo deseja entender um fato que não lhe ficou claro:

De tudo não falo. Não tenciono relatar ao senhor minha vida em dobrados passos; servia para quê? Quero é armar o ponto dum fato, para depois lhe pedir um conselho. Por daí, então, careço de que o senhor escute bem essas passagens: da vida de Riobaldo, o jagunço. Narrei miúdo, desse dia, dessa noite, que dela nunca posso achar o esquecimento. O jagunço Riobaldo. Fui eu? Fui e não fui. Não fui? - porque não sou, não quero ser. Deus esteja! (ibidem, p.232)

Objetivando armar um fato de sua vida, Riobaldo faz um longo relato, que inicia em sua infância: "O senhor sabe: a coisa mais alonjada de minha primeira meninice, que eu acho na memória foi o ódio, que tive de um homem chamado Gramacedo...” (ibidem, p.58), se estende em sua vida de jagunço e acaba trazendo alguns pormenores do seu presente. Nesta narrativa o velho inclui julgamentos sobre si mesmo e sobre o que fez, e também comparações dos tempos passados com os atuais. 
Vi tanta cruez! Pena não paga contar; se vou, não esbarro. E me desgosta, três que me enjoa, isso tudo. Me apraz é que o pessoal, hoje em dia, é bom de coração. Isto é, bom no trivial. Malícias maluqueiras, e perversidades, sempre tem alguma, mas escasseadas. Geração minha, verdadeira, ainda não era assim. Ah, vai vir um tempo, em que não se usa mais matar gente... Eu, já estou velho. (ibidem, p.38)

Essa "rememoração também significa uma atenção precisa ao presente, em particular a estas estranhas ressurgências do passado no presente, pois não se trata somente de não esquecer do passado, mas também de agir sobre o presente. A fidelidade ao passado, não sendo um fim em si mesma, visa à transformação do presente" (GAGNEBIN, 2006, p.55). Riobaldo quer transformar este presente, quer se livrar do passado que ele julga ter sido de muitos erros: "Minha velhice já principiou, errei toda conta".(ROSA, 2001, p.31)

Depois de já ter visto muita coisa na vida, "até cavalo com soluço" (ibidem, p.30), o narrador descobre que "às vezes é só feito menino..." (ibidem, p.41) e que agora precisa de alguém que lhe preste atenção e repense as suas palavras, pois tudo nelas é aviso: "O senhor pode rir: seu riso tem siso. Eu sei. Eu quero é que o senhor repense as minhas tolas palavras. E, olhe: tudo quanto há é aviso". (ibidem, p.186)

Ao contar sua história, o velho Riobaldo não almeja elencar os fatos mais importantes. $\mathrm{Na}$ verdade, ele vai recolhendo os cacos do passado para remontar um todo com significação. A narrativa acaba não sendo linear, é um descontínuo, é a erupção de um vulcão com um diferencial: as larvas não são destruidoras, mas construtoras.

Hoje em dia, verso isso: emendo e comparo. Todo amor não é uma espécie de comparação? E como é que o amor desponta. Minha Otacília, vou dizer. Bem que eu conheci Otacília foi tempo depois; depois se deu a selvagem desgraça, conforme o senhor ainda vai ouvir. Depois após. Mas o primeiro encontro com ela, desde de já conto, ainda que esteja contando antes da ocasião. Agora não é que tudo está me subindo mais forte na lembrança? Pois foi. (ibidem, p.73)

Na memória de Riobaldo estão os vestígios de um passado que não é somente dele, mas é também de outros. Quando se vê como velho, relembra do velho padrinho e compara os sentimentos de ambos na velhice. O padrinho sentiu remorsos por ele, ou seja, inquietude por não ter assumido a paternidade; Riobaldo, porém, está arrependido, o que é diferente, já que arrependimento significa contrição, mudança de opinião. Na velhice ele declara que desde de jovem achava que a vida andava em erros e que deveria ser como num teatro, onde os papéis estão estabelecidos e fixados, onde os atores desempenham com forte gosto o seu papel.

Mesmo o que eu recebi eu menos merecia. Agora, derradeiramente, destaco: quando velho, ele penou remorso por mim; eu velho, a curtir arrependimento por ele. Acho que nós dois éramos mesmo pertencentes. (ibidem, p.131)

Em desde aquele tempo, eu achava que a vida da gente vai em erros, como um relato sem pés nem cabeça, por falta de sisudez e alegria. Vida devia de ser como na sala de teatro, cada um 
inteiro fazendo com forte gosto seu papel, desempenho. Era o que eu acho, é o que eu achava. (ibidem, p.260-261)

Ao olhar e narrar o seu passado, o velho Riobaldo se liberta dos males do presente, pois o passado, com seus erros e acertos, é fonte de conselhos para o presente e nascente de profecias para o futuro.

Do que hoje sei, tiro passadas valias? Eh - fome de bacurau é noitezinha [...] Maiores vezes, ainda fico pensando. Em certo momento, se o caminho demudasse - se o que aconteceu não tivesse acontecido? Como havia de ter sido a ser? Memórias que não me dão fundamento. $\mathrm{O}$ passado - é ossos em redor de ninho de coruja... E, do que digo, o senhor não mal creia: que eu estou bem casado de matrimônio - amizade de afeto por minha bondosa mulher, em mim é ouro toqueado. (ibidem, p.537-538)

\section{A arte de contar e contar-se}

Ao contar sua própria história, o narrador busca nas suas recordações pessoas e acontecimentos que sejam significativos para o fim da narração. Riobaldo, ao narrar a sua vida, intenta armar um fato que não lhe ficou claro, e depois pedir um conselho ao seu interlocutor, logo faz a seleção das pessoas e fatos interessantes para aquele instante de enunciação. Ao ler $G S V$, percebemos, como dissemos acima, o tom expiatório, logo as falas de Riobaldo não constituem um diálogo dele com o seu interlocutor, são uma fala dele com ele mesmo. Objetivando "armar um ponto da vida" ele narra a sua história, contando-a desordenadamente, e desta forma, chega ao sombrio das coisas e com isso pretende a afastar de si o que é ruim dentro dele.

Não devia de estar lembrando isto, contando assim o sombrio das coisas. Lenga-lenga! Não devia de. O senhor é de fora, meu amigo mas meu estranho. Mas, talvez por isto mesmo. Falar com o estranho assim, que bem ouve e logo longe se vai embora, é um segundo proveito: faz do jeito que eu falasse mais mesmo comigo. Mire veja: o que é ruim, dentro da gente, a gente perverte sempre por arredar mais de si. Para isso é o muito se fala? (ibidem, p.55)

Michael Foucault, em 1976, apresentou um conjunto de textos sobre a história da sexualidade, nestes, ele aponta que no momento da confissão religiosa o ouvinte tem ação de controle sobre o confidente. Muitos estudiosos modernos avaliam que esse controle ultrapassa o ambiente religioso, estas condições são verificadas em qualquer situação, na qual o indivíduo tenha a necessidade de autorização do seu discurso, principalmente quando nos enunciados esteja contida a própria subjetividade e seus conteúdos mais íntimos. Quando pensamos em $G S V$, temos apenas a voz do confidente, não nos é permitido conhecer o ouvinte, sabemos apenas que ele é um doutor citadino e, por ele não se apresentar, não podemos inferir com exatidão que tipos de controle ele poderia exercer sobre o discurso do narrador. Porém, acreditamos que Riobaldo não está preocupado com o interlocutor, este é 
apenas um mote para que as suas palavras jorrem e o seu contar se transforme em expiação. Riobaldo faz voltas, se repete, conta pormenores pouco interessantes e questiona a sua arte de narrar. Vemos neste recontar uma estratégia do narrador, pois reconta a fim de melhor entender-se e de alguma forma libertar-se dos sentimentos que lhe imprimem arrependimento.

Sei que estou contando errado, pelos altos. Desemendo. Mas não é por disfarçar, não pense. De grave, na lei do comum, disse ao senhor quase tudo. Não cio receio. O senhor é homem de pensar o dos outros como sendo o seu, não é criatura de pôr denúncia. E meus feitos já revogaram, prescrição dita. Tenho meu respeito firmado. Agora, sou anta empoçada, ninguém me caça. Da vida pouco me resta - só o deo-gratias; e o troco. [...] Eu estou contando assim, porque é o meu jeito de contar.(ROSA, 2001, p.114)

A verdade é que em minha memória, mesmo, ela tinha aumentado de ser mais linda. Eu sei que o que estou dizendo é dificultoso, muito entrançado. Mas o senhor vai avante. Invejo é a instrução que o senhor tem. Eu queria decifrar as coisas que são importantes. Eu estou contando não é uma vida de sertanejo, seja se for de jagunço, mas a matéria vertente. Queria entender do medo e da coragem, e da gã que empurra a gente para fazer tantos atos, dar corpo ao suceder. O que induz a gente para más ações estranhas é que a gente está pertinho do que é nosso, por direito, e não sabe, não sabe, não sabe! (ibidem, p.116)

Riobaldo acaba falando daquilo que não sabe, que ele chama sertão, não apenas o sertão espaço geográfico, onde ocorreu sua história, mas o seu sertão interior, as veredas internas que ele precisa percorrer. Ele não narra qualquer história ou fato, ele lembra, pondera e dá voz às impressões ou às inquietações que subitamente vão aparecendo. Este jogo faz com que a narrativa perca a sua linearidade: não temos uma seqüência de episódios ou acontecimentos da vida de Riobaldo ou dos sertanejos, mas sim fatos que vão surgindo e permitem que o narrador viaje por suas veredas íntimas, se conhecendo e reconhecendo.

Sendo isto. Ao doido, doideiras digo. Mas o senhor é homem sobrevindo, sensato, fiel como papel, o senhor me ouve, pensa e repensa, e rediz, então me ajuda. Assim, é como conto. Antes conto as coisas que formaram passado para mim com mais pertença. Vou lhe falar. Lhe falo do sertão. Do que não sei. Um grande sertão! Não sei. Ninguém ainda não não sabe. Só umas raríssimas pessoas - e só essas poucas veredas, veredazinhas. O que muito lhe agradeço é a sua fineza de atenção. (ibidem, p.116)

Não me esqueci de nada, o senhor vê. Aquele menino, como eu ia poder deslembrar? (ibidem, p.120)

"Para que referir tudo no narrar, por menos e menor?" (ibidem, p.154-155) Quando pensa no seu narrar, Riobaldo abre a antiga discussão sobre o que é necessário referir ao contar uma história. Ele coloca a narrativa de suas memórias num "entre-lugar", ou seja: é narrativa de um eu que volta ao passado para compreender o presente; é narrativa que vive entre o esquecimento e a lembrança, entre o particular e o coletivo, entre a construção da atual identidade e a impossibilidade de reconstruir o passado. Esta multiplicidade da narrativa impede que se tenha a clássica idéia de história fixa do passado, ela nos remete ao conceito de construção: ao narrar, além de atar as pontas que ficaram soltas, Riobaldo consegue ver a 
história como sendo somente sua, pois no momento do vivido ela era de todos, ficando difícil precisar pormenores.

Aquele encontro nosso se deu sem o razoável comum, sobrefalseado, como do que só em jornal e livro é que se lê. Mesmo o que eu estou contando, depois é que eu pude reunir lembrado e verdadeiramente entendido - porque, enquanto coisa assim se ata, a gente sente mais é que o corpo próprio é: coração bem batendo. Do que o que: o real roda e põe diante. "Essas são as horas da gente. As outras, de todo tempo, são as horas de todos".(ibidem, p.154155)

O ex-jagunço se considera com boa memória, orgulha-se de não ter esquecido de nada, pois os fatos e pessoas foram tão significativos que seria completamente impossível ele "deslembrar". Afirma não ter remorsos de sua vida passada, atribuindo a responsabilidade pelos seus feitos a aspectos divinos: liga os maus ao pacto, e os bons a Deus. Ele não assume a posição de santo arrependido, já que estes enxergam uma luz na escuridão; o nosso narrador tem boa memória, ou seja, está na luz, logo contar o seu passado proporciona o autoconhecimento e lhe dá garantias de expiação dos maus feitos.

Desculpa me dê o Senhor, sei que estou falando demais, dos lados. Resvalo. Assim é que a velhice faz. Também, o que é que vale e o que é que não vale? Tudo. Mire veja: sabe porque é que eu não purgo remorso? Acho que o que não deixa é minha boa memória. A luzinha dos santos-arrependidos se acende é no escuro. Mas eu lembro de tudo. Teve grandes ocasiões em que eu não podia proceder mal, ainda que quisesse. Por que? Deus vem guia a gente por uma légua, depois larga. Então, tudo resta pior do que era antes. Esta vida é de cabeça para baixo, ninguém pode medir suas perdas e colheitas, mas conto. Conto para mim, conto para o senhor. Ao quando bem não me entender, me espere. (ibidem, p.160-161)

Ao construir a sua verdade sobre si mesmo, no processo do contar, Riobaldo procura não incomodar o seu ouvinte, quer contar as passagens de sua vida diferente do Garanço, que importunava as pessoas com suas histórias. O narrador tem consciência de que não acerta no contar, pois ele anda a procura do rumo das coisas, algo que, segundo ele, não é fácil de encontrar. Ao considerar o passado acabamos dando-lhe novas significações, o que faz com que os indivíduos repensem os fatos e acabem referindo-os mais de uma vez, a fim de tentar certificarse, ou precisar melhor, o dito.

O Garanço era sanfranciscano, dum lugar chamado Morpará. Hás-de, queria que agente escutasse ele recontar compridas passagens de sua vida. Aquilo aborrecia. Eu queria estarestâncias: dos violeiros, que tocavam sentimento geral. (ibidem, p.91)

O senhor sabe? Não acerto no contar, porque estou remexendo no vivido longe alto, com pouco caroço, querendo esquentar, demear, de feito, meu coração, naquelas lembranças. Ou quero enfiar a idéia, achar o rumozinho forte das coisas, caminho do que houve e não houve. Às vezes não é fácil. Fé que não é. (ibidem, p.192)

Pensar em memória como construção, exige que tenhamos clareza de que o passado está sendo reconstruído no presente, ou seja, a história está sendo contada por um outro 
homem, possuidor de novas vivências, de novas necessidades e de novas emoções. No caso de Riobaldo, a história é contada pelo fazendeiro, ou seja, ele no presente ocupa uma posição antagônica ao seu passado. O fazendeiro tem noção de em alguns momentos: "O que eu sinto, e esforço em dizer ao senhor, repondo minhas lembranças, não consigo; por tanto é que refiro tudo nestas fantasias". (ibidem, p.304) Além de fantasiar nossa história, somos levados pelos sentimentos, no caso do nosso narrador, estes sentimentos são românticos, pois para ele sentimento é sinônimo de Diadorim, embora esteja casado com Otacília.

[...] todas as minhas lembranças eu queria comigo. Os dias que são passados vão indo em fila para o sertão. Voltam, como os cavalos: os cavaleiros na madrugada - como os cavalos se arraçôam. [...] Jagunço é o sertão. O senhor pergunte: quem foi que foi o jagunço Riobaldo? [...] Todos os sucedidos acontecendo, o sentir forte da gente - o que produz os ventos. Só se pode viver perto de outro, e conhecer outra pessoa, sem perigo de ódio, se a gente tem amor. Qualquer amor já é um pouquinho de saúde, um descanso na loucura. Deus é quem sabe. O Reinaldo era Diadorim - mas Diadorim era um sentimento meu. (ibidem, p.327)

Segundo Gagnebin (1994), a guerra nos coloca frente ao indizível, e quem volta dela tem uma "narração insuportável", assim ao aceitar ouvir a história do outro nos revezamos com ele na transmissão simbólica, assumindo a responsabilidade de repassá-la, para que através da reflexão sobre ela possa-se inventar um presente sem guerras. Riobaldo tem consciência destes momentos indizíveis, os quais não são possíveis contar: "A guerra tem destas coisas, contar é que não é plausível”.(ROSA, 2001, p.380) Mas ao contrário de Gagnebin, ele não acredita que o outro possa ser transmissor desta história, para o ex-jagunço, somente através da vivência é que se é capaz de adquirir experiência: "De que lhe serve eu lhe contar minuciado - o senhor não padeceu feliz comigo -? Saber as revezadas do capim?” (ibidem, p.387). Assim ele, mais uma vez, evidencia que o seu narrar é apenas expiatório, não tem o sentido de transmissão de conhecimento, proposto pela autora.

Além de pensar sobre as estratégias narrativas, Riobaldo pensa sobre os seus esquecimentos e mesmo para eles o narrador consegue argumentos que o justifiquem. À dificuldade de lembrar de pormenores do relacionamento com Diadorim, ele associa ao fato de terem vivido muito próximos, não admitindo a possibilidade de ter, de alguma forma, se esquivado do amigo por questões de sexualidade. Mesmo no presente, quando já sabe que Diadorim era uma mulher, Riobaldo se refere a um 'ele'. Riobaldo nega à memória o direito de recordar das situações em que ele esteve mais vulnerável, embora admita todo o tempo o seu grande afeto por Diadorim.

O senhor veja: eu, de Diadorim, hoje em dia, eu queria recordar muito mais coisas que valessem, do esquisito e do trivial; mas não posso. Coisas que se deitaram, esqueci fora do rendimento. $\mathrm{O}$ que renovar e ter eu não consigo, modo nenhum. Acho que é porque ele estava sempre tão perto demais de mim, e eu gostava demais dele. (ibidem, p.394) 
Paul Zumthor (2003) diz que o contador de histórias é uma personagem capaz de fazer com que o tempo abstrato transforme-se em tempo vivido. Ao ouvirmos uma história, o tempo pode deixar de ser marcado cronologicamente, se entrarmos numa escuta desatenta. Esta escuta possibilita a presentificação da história: o ato de narrar/ouvir passa a ser o espaço onde o narrado, o narrador e o ouvinte estão imersos. Esta escuta flutuante nos conduz a um estado de graça que só é alcançado pela suspensão do tempo exterior, ou seja, este ato é necessário para que entremos no tempo circular e mítico do mundo interior.

Ao falar destes encantos narrativos, Zumthor se refere ao narrador oral, de certa forma as referências são as tradicionais histórias à volta da fogueira. Riobaldo pode ser tido como este narrador, pois o engenho de Guimarães Rosa faz com que o leitor, esqueça-se de que o seu papel é ler. Ele assume o lugar do doutor-ouvinte do ex-jagunço, ouve as confissões de um homem que vai contando e soltando as palavras na expectativa de encontrar um caminho de tranqüilidade que o justifique, ou que ao menos lhe permita entender sua vida.

Falo por palavras tortas. Conto minha vida, que não entendi. O senhor é homem muito ladino, de instruída sensatez. Mas não se avexe, não queira chuva em mês de agosto. Já conto, já venho - falar no assunto que o senhor está de mim esperando. (ROSA, 2001, p.506)

\section{Conclusão}

À narrativa confessional de Riobaldo, o contar a sua história passa a ser vereda para o saber. Na perspectiva de autoconhecimento, a narrativa assume a mesma importância da ciência, da religião ou da filosofia, porque vai significando o real. "Verdade e sentido não se encontram na narração nem no narrado, mas em um "além" que pertence à interpretação e ao ato hermenêutico." (ROSENFIELD, 2006, p.204). Chega-se ao conhecimento durante a “travessia”, não após ela, porque ele está no próprio discurso. Sendo assim, a narrativa de Riobaldo não pode ter forma fixa, nem fechar-se, exclusivamente, em uma lógica; é narrativa em cuja organização o narrador busca mais do que retirar princípios ou idéias, ele almeja ultrapassar os limites racionais do ato de contar.

Ao visitar o seu passado, o velho Riobaldo, ex-jagunço, atual fazendeiro respeitado, se apresenta como uma figura de um sujeito de identidade ambivalente, pois é oscilando entre o amor de Diadorim e das mulheres, entre Deus e o diabo, nas contradições e tensões é que sua identidade será animada (ROSENFIELD, 2006). 
Viver o que faltava é para nós o marco deste trabalho. Contar nossa história, nossos feitos faz parte da vida e ouvir os feitos de outrem é indispensável para viver. Advindo daí a necessidade de Riobaldo contar, jorrando como um rio, a vida que não entendeu.

Tudo isto, para o senhor, meu senhor, não faz razão, nem adianta. Mas eu estou repetindo muito miudamente, vivendo o que me faltava. Tão mixas coisas, eu sei. Morreu a lua? Mas eu sou do sentido e do reperdido. Sou do deslembrado. Como vago vou. E muitos fatos miúdos aconteceram.

Eu me cerro, aqui, mire e veja. Isto não é o de um relatar passagens de sua vida, em toda admiração. Conto o que fui e vi no levantar do dia. Auroras.

Cerro. O senhor vê. Contei tudo. Agora estou aqui, quase barranqueiro. Para a velhice vou, com ordem e trabalho. Sei de mim? Cumpro. O rio São Francisco - que de tão grande se comparece - parece é um pau grosso, em pé, enorme... Amável o senhor me ouviu, minha idéia confirmou: que o Diabo não existe. Pois não? O senhor é um homem soberano, circunspecto. Amigos somos. Nonada. O diabo não há! É o que eu digo, se for... Existe é homem humano. Travessia. (ROSA, 2001, p.623-624)

\section{Referências}

BENJAMIN, Walter. KOTHE, Flávio (Org.). Walter Benjamin. São Paulo: Ática, 1985.

BOSI, Ecléia. Memória e Sociedade: lembrança dos velhos. São Paulo: T.A. Queiroz, 1983.

FOUCAULT, M. História da Sexualidade I: A Vontade de saber. Rio de Janeiro: Graal, 1997.

GAGNEBIN, J. M. História e narração em W. Benjamin. São Paulo: Perspectiva, 1994.

HALL, Stuart. A Identidade Cultural na Pós-Modernidade. Rio de Janeiro: DP\&A Editora, 2006.

NUNES, Lucília. By the hand of Ricoeur and Arendt: Identity and History. Speaking of Historical Memory. Temperamentvm. Disponível em http://www.indexf.com/temperamentum/tn6/t3807p.php. Acesso em 23 fev 2008.

ROSA, Guimarães. Grande Sertão: Veredas. Rio de Janeiro: Nova Fronteira, 2001.

ROSENFIELD, Kathrin. Desenveredando Rosa: a obra de J.G. Rosa e outros ensaios rosianos. Rio de Janeiro: Topbooks , 2006.

ZUMTHOR, Paul. A letra e a voz. São Paulo: Companhia das Letras, 1993. 